\title{
EFFECT OF BODY-WORN CAMERAS ON AFRICAN-AMERICAN PERCEPTIONS OF POLICE PERFORMANCE AND FAIRNESS
}

Author ORCID: https://orcid.org/0000-0002-1631-1159

Author Affiliation: Yolanda N. Smith, Ph.D., Capella University, Minneapolis, Minnesota, SC Classification Genre: Criminal Justice

\section{Creative Commons Attribution (c) (1) (2)}

Citation: Smith, Y. (2021). Effect of body-worn cameras on African-American perceptions of police performance and fairness. Scholar Chatter 2(1), 44-56, http://doi.org/10.47036/SC.2.1.44-56.2021

(C) The Author. 2021. This is an open access publication through Scholar Chatter LLC.

\begin{abstract}
This research study examined the effect of body-worn cameras on African American perceptions of police performance and fairness to gain a well-rounded understanding of the public's perception of body-worn cameras. Prior research involving police body-worn cameras focused on police use of force and community perceptions. Limitations within previous research call for further investigation into African American perceptions of the police and consider the role bodyworn cameras play in affecting that perception. Using procedural justice theory, I focused on body-worn cameras and their effect on African-American perceptions of police performance and fairness. Employing a quantitative, non-experimental research design and surveying 124 African-American adult participants 18 years and older, I found that African-Americans favor police officers who wear body-worn cameras. Future research suggests incorporating a greater sample size, thereby strengthening the validity and improving generalizability. Policy implications suggest that studying body-worn cameras may add additional research to the knowledge base and help law enforcement understand the relationship between police officers who wear body-worn cameras and African-Americans perceptions of police treatment when body-worn cameras are present.
\end{abstract}

Keywords: African-American, body-worn cameras, police performance, fairness, procedural justice 


\section{Introduction}

Police use of force and citizen complaints are at the center of the public's perception of law enforcement (Demir, 2019). Unjustified shootings of unarmed African-Americans sparked public concern regarding police use of force and strained police and public relations within the African-American community (Passavant, 2015). The police shootings of Eric Garner and Michael Brown and now the knee on George Floyd's neck cast a negative light on policing and generated a national debate concerning police accountability (Passavant, 2015). As police use of force incidents increased, community outcry for police reform and oversight continued to grow. Police departments across the country and worldwide turned to body-worn camera (BWC) technology to address societal concerns over police behavior and performance.

BWCs are a technology new to the law enforcement arena. Global consideration for using BWCs is increasing as a tool to aid law enforcement agencies in solving crimes and overseeing police professionalism (Coudert et al., 2015; Cubitt et al., 2016). Preliminary examinations of BWCs incorporated the police's use of force and accountability. Further probing included the public's perception of law enforcement and police perceptions of BWC while performing their duties (Coudert et al., 2015; Jennings et al., 2014; Smykla et al., 2016). Due to minimal studies on public perceptions of BWCs among African-Americans, considering the relationship between attitudes about BWCs and African-American perceptions of police performance and fairness is crucial.

Exploring BWC's effect on African-American perceptions of police performance and fairness will benefit researchers and practitioners by demonstrating the role BWCs play during police encounters with African-Americans. This research study contributes to a growing field of knowledge by depositing new research into the knowledgebase. The benefit may further help law enforcement agencies make informed decisions about future policy design concerning police BWCs and their use and help police agencies understand the relationship between police officers and the African-American community when the equipment is present.

Procedural justice theory is the most compelling theory in examining the role BWCs play in the African-American perception of police performance and fairness. Procedural justice theory holds that when police officers treat people fairly and respectfully, legitimacy increases (Tyler, 1988). As a part of my study, I examined the research questions: how do the attitudes about police BWCs, age, and sex affect the perception of police performance among AfricanAmericans age 18 and older, and how do the attitudes about police BWCs, age, and sex affect the perception of police fairness among African-Americans age 18 and older?

\section{Literature Review}

The sources of information used to review the literature comprised of peer-reviewed works from various databases. A review of the literature suggests contrasting views concerning the public's perception of BWCs. The idea ranges from support for the gadget because of police accountability and legitimacy and citizen compliance to rejecting BWCs due to costeffectiveness, autonomy, and privacy issues. Researchers examined the public's perception of BWCs relating to police officers' use of force and police performance. Still, the literature 
suggests exploring how BWCs affect the African-American perception of police performance and fairness.

High-profile police shooting incidents, political agendas, and a call for police reform stimulated law enforcement's use of BWC technology (Lum et al., 2019). BWCs are small devices that a police officer attaches to their bodies and record their public encounters (Kahn \& Martin, 2016). Audio and video means may retrieve these recordings. The expectation is that the apparatus will inspire citizen compliance with the police, lessen citizen complaints against the law enforcement officers, reduce the police use of force, and increase police accountability.

The evolution of police BWCs stems from the strained relationship between the police and its community. High-profile police shooting incidents, political agendas, and a call for police reform influence using the new technology (Lum et al., 2019). To enhance legitimacy and increase public trust, police departments began increasing their training efforts and enhancing their technology by incorporating BWCs to improve the relationship between the citizens and the police.

African-Americans are predisposed to police violence due to cultural biases, ineffective police training measures, and administrative policies (Carbado \& Rock, 2016; Chaney \& Robertson, 2014). In response to biased policing, in 2014, President Barak Obama appealed to Congress for funding to aid police departments in purchasing BWCs and providing additional law enforcement training on racial sensitivity and implicit bias (Kahn \& Martin, 2016). The arrival of police BWCs unveiled a novel technique that could help tackle issues that fuel local and global changes in police performance, training, policies, and procedures.

African-American support for BWCs has considered the police's use of BWCs a panacea for bridging the gap between the police and the public. A cure-all for resolving police misconduct issues, BWCs provide an objective view of police and citizen encounters (Graham et al., 2019). Research findings of perceptions of BWCs concluded that police departments that equipped police officers with BWCs influenced an increase in citizen cooperation and saw citizen complaints decreased (Jennings et al., 2014; White et al., 2017). The appearance of BWCs obtained public buy-in and support.

BWCs' purpose is to resolve the mistrust between the police and the community, promote police accountability and transparency, change police and citizen behavior, and guide the participant and stakeholder perceptions of the monitoring device (Ariel, 2016; Coudert et al., 2015; Kahn \& Martin, 2016). Police officers recognized that wearing BWCs might hamper police officers' ability to do their job (Taylor, 2016). In juxtaposition, researchers exploring police officers' perception of BWCs found that police officers armed with BWCs supported the idea and approved the technology (Drover \& Ariel, 2015; Smykla et al., 2016). After training and engagements, officers did not believe that the instrument could adversely affect their job performance.

Researchers determined that police performance can have a lasting effect on whether citizens accept or reject police practices and the public's perception of the police (Aviv \& Weisburd, 2016). Research that explored police performance perceptions showed that citizens 
perceived BWCs as beneficial to police performance (Crow et al., 2017). Citizens associated the perception of police performance with how fair and just police officers treated citizens.

Objective supervision is concomitant to fair policing. Although there is no constitutional requirement for a police officer to treat citizens respectfully and kindly, people evaluate law enforcement performance based on the encounter (Meares et al., 2015; M. Van Craen \& Skogan, 2017). Researchers investigating fair policing found that fair-minded policing was commensurate with adequate supervision of officers wearing BWC. When police supervisors exhibited fairness to their subordinates, police officers treated encountered citizens fairly (M. Van Craen, 2016). Police officers will imitate their supervisors' behavior and demonstrate fairness externally when they receive fair treatment internally (M. Van Craen, 2016). Police department policy, supervision, and training are a few ways police departments have attempted to enhance their agents' fairness.

\section{Methodology}

I used a quantitative non-experimental design method to describe the problem and regression analysis to predict the effect that BWCs have on African-American perceptions of police performance and fairness. The purpose of using a quantitative, non-experimental design method was to determine if and to what extent the attitudes about police BWCs, age, and sex affected the perceptions of police performance and fairness among African-Americans. This research study focused on African- American adults within the United States, age 18 and older.

\section{Research Questions and Hypotheses}

This research study, conducted in the summer of 2020 in the United States, incorporated research questions and hypotheses to examine what effect BWCs, sex, and age had on the African-American perception of police performance and fairness. Procedural justice theory is the theoretical framework used in examining the predictive factors of age, sex, and the attitudes of a BWC to identify any statistical relationships (Smith, 2020). Conducting this study required a quantitative non-experimental research design with a multiple regression statistical analysis Non-experimental studies prohibit the manipulation of the variables. A non-experimental design is less rigorous, and its purpose was to be purely descriptive (Smith, 2020). The research examined the following research questions and hypotheses and rejected the null hypotheses:

\section{Research Question 1}

How do the attitudes about police BWCs, age, and sex affect the perceptions of police performance among African-Americans age 18 and older?

H1: There is a relationship between the attitudes about police BWCs, age, sex, and the perceptions of police performance among African-Americans age 18 and older.

\section{Research Question 2}

How do the attitudes about police BWCs, age, and sex affect the perceptions of police fairness among African-Americans age 18 and older? 
$\boldsymbol{H}_{1}$ : There is a relationship between the attitudes about police BWCs, age, sex, and the perceptions of police fairness among African-Americans age 18 and older.

I exercised a non-experimental design method that described the problem and regression analysis that predicted African-American perceptions about police officers using BWCs. Surveys and questionnaires are a conventional design method for quantitative non-experimental research (Thompson \& Panacek, 2007). This research study integrated a survey instrument comprised of a predetermined number of questions and answers, making it an appropriate method for answering the research questions.

\section{Target Population and Sample}

The research targeted African-Americans from various social, economic, and educational backgrounds within the United States. It did not require that proposed participants live in a specific location, for instance, an urban or suburban community, to partake in the research (Smith, 2020). The research encompassed 124 African-American adults age 18 and over who voluntarily elected to contribute to this research study. Participants completed a consent form and answered pre-qualifying questions before taking the online survey. The inclusion process required that participants were African-American adults, at least 18 years old, and provide consent (Smith, 2020). This research study excluded individuals who were not AfricanAmerican and under age 18 from participating in the survey. Also excluded from the data results were individuals who did not answer any survey questions and refused consent to participate in the research.

\section{Procedures}

\section{Data Collection}

This research study employed one survey instrument consisting of three subscales that measured the variables and constructs. Participants took approximately 4 minutes to read and provide consent to enter the survey. Participants had the option of printing or downloading a copy of the consent form for their records. Consideration for this research study required that the participant is an African-American adult, age 18 and older. Once the participant provided consent, he or she entered the survey to complete it. The data were collected using Qualtrics, an online data collection tool. I collected data in the early summer, 2020. Participants took 2.5 to 27.77 minutes to complete the survey $(M=5.94, S D=3.98)$ with a median of 4.74 minutes. This research study employed a single survey instrument that included demographical questions and scales. The survey instrument comprising three subscales used a seven-point Likert-type scale format (Ingham-Broomfield, 2014). The subscales were the Procedural Fairness Scale, Police Performance Scale, and Body-worn Camera Scale.

\section{Data Analysis}

Descriptive statistics. Descriptive and inferential statistical procedures described and analyzed the data. I used descriptive statistics to determine the independent variables' effect on 
the dependent variables (Gelo \& Gallucci, 2016). Inferential statistics tested the hypothesis. This research study incorporated multiple regression analyses to test the research hypotheses.

\section{Instruments}

The original baseline survey contained five subscales; Procedural Fairness, Police Performance, Crime Concern Scale, Body-worn Camera Scale, Privacy Concern Scale, and Body-Worn Cameras Scale. The baseline instrument was normed for residents in two counties in the southern United States (Crow et al., 2017). To construct and validate the measures, the authors used "structural equation modeling software to perform confirmatory factor analysis" ( $\mathrm{p}$. 599). The measurement model included the fit and modification indices, which revealed improvements to the latent constructs (Crow et al., 2017). The author of the instrument permitted me to modify the tool's structure to accommodate the research.

\section{Community BWC Survey Questions}

Validity. The scales' factor loadings were statistically significant with measures above 60 (Crow et al., 2017, p. 599). The measurement model provided factor loadings, multiple fit, and modification indices commonly used in criminal justice research (Gau, 2014). The comparative fit index considers values of -0.90 a good fit and values of 0.95 or above a perfect fit (Gau, 2014). The instrument used in this research study, valued at 0.93 on the comparative fit index, made for a robust measurement model and proved confident in the convergent validity of the measures.

Reliability. For this research study, Cronbach's alpha tested the reliability of the instrument. "The multiple fit indices calculated the reliability coefficient; comparative fit index (CFI), standardized root mean square residual (SRMR), Tucker-Lewis index (TLI), and root mean square error of approximation (RMSEA)." (Crow et al., 2017, p. 599). The combined fit indices and factor loading for the three scales reveal the instrument is a sound measurement model and provide confidence in the convergent validity of the measures.

\section{Table 1.}

Frequency of Police Interaction

\begin{tabular}{|c|c|c|c|c|c|}
\hline Question & Never (\%) & Rarely (\%) & Sometimes (\%) & Often (\%) & Always (\%) \\
\hline $\begin{array}{l}\text { How frequently do you } \\
\text { interact with the police in } \\
\text { your area? }\end{array}$ & $36(29.0)$ & $63(50.8)$ & $16(12.9)$ & $7(5.6)$ & $2(1.6)$ \\
\hline $\begin{array}{l}\text { How frequently do you } \\
\text { encounter police who wear } \\
\text { body cameras? }\end{array}$ & $51(41.5)$ & $37(30.1)$ & $29(23.6)$ & $5(4.1)$ & $1(0.8)$ \\
\hline
\end{tabular}

Note. 1=One participant did not answer. 
Slightly more than half of the respondents $(53.3 \%, n=64)$ described their interactions with the police in their areas as neutral. Nevertheless, $24.2 \%(n=29)$ described their interactions as positive and $10.8 \%(n=13)$ described their interactions as "very positive." Participants with negative police experiences were in the minority. Specifically, $6.7 \%(n=8)$ described their police interactions as negative and $5.0 \%(n=6)$ described them as very negative. See Figure 1.

\section{Figure 1.}

Description of interactions with police

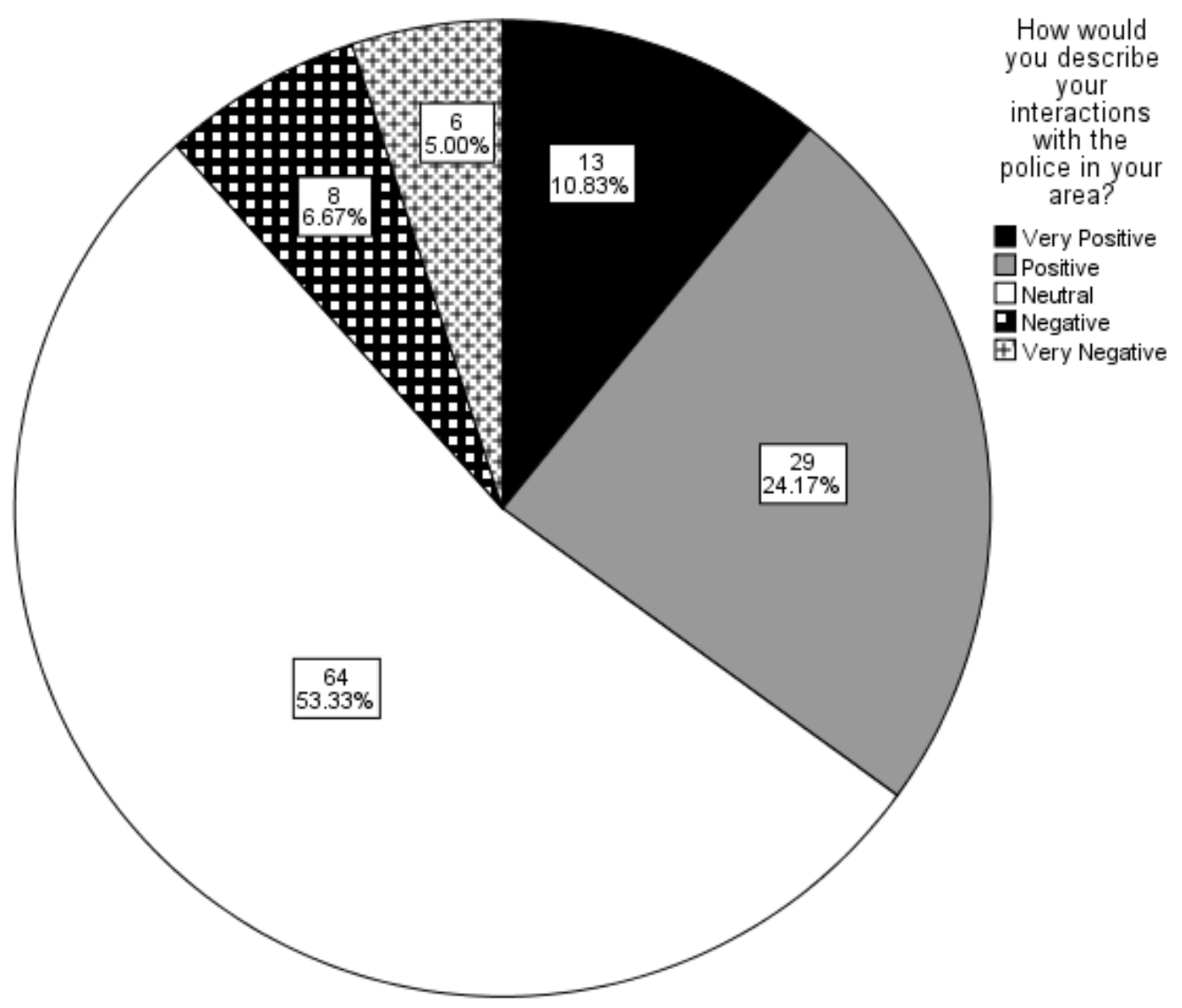

Note. 4 participants did not answer.

\section{Descriptive Statistics}

Computing the mean responses for each item calculated the scores for the variables of interest. The Procedural Fairness Scale is a Likert-type instrument that ranged from 1(strongly disagree) to 7(strongly agree), with higher scores indicating a higher degree of procedural fairness. For perceptions of police fairness, scores ranged from 1.00 to $7.00(M=3.59, S D=$ 1.54). A mean score of 3.59 indicates that, on average, participants had a neutral perception of police fairness. The Police Performance Scale is a Likert-type instrument that ranged from 
1(extremely well) to 7(extremely poorly), with lower scores indicating better performance and higher scores indicating poorer performance. Perceptions of police performance ranged from 1.00 to $6.67(M=3.71, S D=1.33)$. A mean score of 3.71 indicates that, on average, participants perceived police performance to be "slightly well." The Body-Worn Camera Scale is a Likerttype instrument that ranged from 1(strongly disagree) to 7(strongly agree), with higher scores indicating more positive attitudes about BWCs. Scores for attitudes about BWCs ranged from 1.00 to $6.75(M=4.66, S D=1.26)$. A mean score of 4.66 indicates that, on average, participants somewhat agreed that the police wearing body cameras would make the residents safer and improve police officer behavior. Table 2 summarizes the descriptive statistics.

\section{Table 2.}

\section{Descriptive Statistics}

\begin{tabular}{lccccc}
\hline Variable & $n$ & Minimum & Maximum & $M$ & SD \\
\hline Perceptions of Police Fairness & 124 & 1.00 & 7.00 & 3.59 & 1.54 \\
Perceptions of Police Performance & 124 & 1.00 & 6.67 & 3.71 & 1.33 \\
Attitudes About BWCs & 124 & 1.00 & 6.75 & 4.66 & 1.26 \\
\hline
\end{tabular}

\section{Summary of the Hypothesis Testing}

$\mathbf{H}_{\mathbf{0 1}}$ stated that there is no relationship between the attitudes about police BWCs, age, sex, and the perceptions of police performance among African-Americans age 18 and older. The model was statistically significant, thereby rejecting the null hypothesis. $\mathbf{H}_{\mathbf{0 2}}$ stated that there is no relationship between the attitudes about police BWCs, age, sex, and the perceptions of police fairness among African-Americans age 18 and older. The model was statistically significant; therefore, I rejected the null hypothesis. Table 3 summarizes the hypothesis testing results.

\section{Table 3.}

Hypothesis Testing Summary and Outcomes

\begin{tabular}{lccc}
\hline Hypothesis & Statistical Test & Significance & Outcome \\
\hline $\begin{array}{l}\mathrm{H}_{01} \text { : There is no relationship between the attitudes } \\
\text { about police BWCs, age, sex, and the perceptions } \\
\text { of police performance among African-Americans }\end{array}$ & $\begin{array}{c}\text { Multiple } \\
\text { Linear } \\
\text { Regression }\end{array}$ & $p<.001$ & $\begin{array}{c}\text { Null } \\
\text { Rejected }\end{array}$ \\
$\begin{array}{l}\mathrm{H}_{02} \text { : There is no relationship between the attitudes } \\
\text { about police BWCs, age, sex, and the perceptions } \\
\text { of police fairness among African-Americans age } \\
18 \text { and older. }\end{array}$ & $\begin{array}{c}\text { Multiple } \\
\text { Linear } \\
\text { Regression }\end{array}$ & $p<.001$ & $\begin{array}{c}\text { Null } \\
\text { Rejected }\end{array}$ \\
\hline
\end{tabular}




\section{Summary}

Attitudes about BWCs were significantly and positively related to perceptions of police performance and fairness among African-Americans age 18 and older. As positive attitudes about BWCs increased, perceptions of police fairness increased while perceptions of poor police performance decreased. Age was not a significant predictor of perceptions of police fairness while controlling for sex and attitudes about BWCs. Sex was not a significant predictor of perceptions of police fairness while controlling for age and attitudes about body cameras.

\section{Findings}

Participants were asked how frequently they interacted with the police in their areas. Approximately half $(50.8 \%, n=63)$ reportedly rarely interacted with the police, whereas $29.0 \%$ $(n=36)$ never interacted with the police. However, $12.9 \%(n=16)$ sometimes interacted with the police, $5.6 \%(n=7)$ often interacted with the police and $1.6 \%(n=2)$ always interacted with the police. Fort-two percent $(n=51)$ of respondents never encountered police who wear bodycameras, and $30.1 \%(n=37)$ rarely encountered police who wear body cameras. However, $23.6 \%(n=29)$ sometimes encountered police who wear body-cameras, $4.1 \%(n=5)$ often encountered police who wear body-cameras, and $0.8 \%(n=1)$ always encountered police who wear body cameras. See Table 1.

\section{Discussion}

BWCs are a new phenomenon that law enforcement considers using locally and globally. The tenuous relationship between the police and the African-American community leads one to question how BWCs affect African-American perceptions of the police during encounters when the device is present. Although existing studies reveal a positive public perception of BWCs, limitations within the research suggest examining African-American attitudes about BWCs (Coudert et al., 2015). This research study's significance will benefit researchers and practitioners alike by depositing new research into the knowledgebase and demonstrating the role BWCs play during police encounters with African-Americans.

The research concluded that African-American attitudes about BWCs were significantly related to the perceptions of police performance and fairness, thereby rejecting the null hypothesis. Sex and age were not predictors of the perceptions of performance or fairness. This research study findings were consistent with prior research that claimed a positive public perception of BWCs. A regression analysis identified a relationship between attitudes about BWCs and perceptions of police performance and fairness.

This research study revealed that attitudes about BWCs were significantly and negatively related to police performance perceptions. In other words, as attitudes about BWCs increased, the perception of poor police performance decreased. The analysis further exposed a significantly positive relationship between attitudes about BWCs and perceptions of fairness. One interesting finding was that age and sex did not predict perceptions of police performance or fairness substantially. In other words, where prior research has shown varying views of police perception between older and younger people, the analysis depicted no connection between sex and age and police performance or police fairness (Pollock \& Menard, 2015). In this research study, age and sex did not matter because race was solely significant. 
The participants were asked how frequently they interacted with the police in their areas. Many of the respondents reported having some interaction with the police in their area. Nearly half of the participants reported never having interactions with police officers who wear BWCs. When asked about their experiences with the police, many of the participants remained neutral in their responses. Some respondents reported having positive experiences with the police. Overall, respondents with negative police experiences were in the minority. On average, participants somewhat agreed that the presence of BWCs would improve police officers' behavior and make the residents safer.

\section{Conclusion}

African-Americans are disproportionately likely to encounter the police negatively. Many police encounters have resulted in death, heightening African-American negative perceptions of the police (Krieger et al., 2015). Police reforms like BWCs may help quail people's anxieties within the African-American community (Ray et al., 2017). Exploring how BWC technology affects police perceptions within the African-American community can help researchers and practitioners better understand how to resolve the conflict and quiet the fears that continue to haunt members within the African-American community.

This research study examined the effects of BWCs on African-American perceptions of police performance and fairness. Indicatively, this research study assessed how the attitudes about police BWCs, age, and sex affect the perceptions of police performance and fairness among African-Americans age 18 and older. After observing the survey results, this research study's regression analysis identified a relationship between attitudes about BWCs and perceptions of police performance and fairness. The research also identified a connection between the attitudes about BWCs and police fairness.

The research explored the effects of BWCs on the perception of police performance and fairness within the African-American community by examining two separate hypotheses. In support of $\mathbf{H}_{\mathbf{0 1}}$, this research study found a relationship between attitudes about BWCs and the perception of police performance and $\mathbf{H}_{\mathbf{0 2}}$ the perception of police fairness. In support of prior research, the study also found a positive public perception of police BWCs. According to Graham et al. (2019), in a study that examined African-American's support for BWCs, more than $85 \%$ of people surveyed highly supported BWCs. This research study positively supports and confirms the results of prior researchers.

Researching how attitudes about BWCs might affect police perception within the African-American community is significant to the public service society and the law enforcement community because there is a potential benefit to researchers and practitioners alike. This research study may broaden the scholarship by depositing research into the knowledge base and assisting law enforcement agencies in making informed decisions concerning future policy design on implementing a police BWC plan. Studying BWCs may help police agencies understand the relationship between police officers that wear BWCs and how members of the African-American community perceive how the police treat them. 
According to McCluskey et al. (2019), improving police relations between the police and African-Americans does not occur in a vacuum. In other words, accessories alone, such as BWCs, will not change police perception within that community. Moving police behavior toward procedural justice will improve legitimacy and evoke citizen compliance (Tyler, 1988). The procedural justice theory holds those police officers who treat people reasonably enhance legitimacy. The public will comply with police as legitimacy increases (Tyler, 1988). The literature depicts an overall positive public perception of the police. Prior research revealed that members within the African-American community had a negative attitude towards the police (Bradford et al., 2014; Peck, 2015). This research study results inferred a positive public perception of the police within the African-American community. The attitudes about BWCs in this research study influenced the perception.

\section{Funding}

The research for this article was funded solely by the author.

\section{Acknowledgments}

The author thanks all respondents who voluntarily participated in the research. Special thanks to my mentor and dissertation chair, Dr. Nathan Moran. Extended thanks to my committee members Dr. Jeff Schneider and Dr. Stephen Verrill.

\section{References}

Ariel, B. (2016). Increasing cooperation with the police using body-worn cameras. Police Quarterly, 19(3), 326-362. https://doi.org/10.1177/1098611116653723

Aviv, G., \& Weisburd, D. (2016). Reducing the gap in perceptions of legitimacy of victims and non-victims: The importance of police performance. International Review of Victimology, 22(2), 83. https://doi.org/10.1177/0269758015627041

Bradford, B., Murphy, K., \& Jackson, J. (2014). Officers as mirrors: Policing, procedural justice, and the (re)production of social identity. British Journal of Criminology, 54, 527-550. https://doi.org/10.1093/bjc/azu021

Carbado, D. W., \& Rock, P. (2016). What exposes African-Americans to police violence? Harvard Civil Rights-Civil Liberties Law Review, 51(1), 159-187. http://pi.aic.gov.au/resources/what-exposes-African-Americans-police-violence

Chaney, C., \& Robertson, R. V. (2014). "Can we all get along?" Blacks' historical and contemporary (in) justice with law enforcement. Western Journal of Black Studies, 38(2), 108-122. https://doi.org/10.21236/ada573203

Coudert, F., Butin, D., \& LeMetayer, D. (2015). Body-worn cameras for police accountability: Opportunities and risks. Computer Law \& Security Review, 31(6), 749-762. https://doi.org/10.1016/j.clsr.2015.09.00

Crow, M. S., Snyder, J. A., Crichlow, V. J., \& Smykla, J. O. (2017). Community perceptions of police body-worn cameras. Criminal Justice and Behavior, 44(4), 589-610. https://doi.org/10.1177/0093854816688037 
Cubitt, T. I., Lesic, R., Myers, G. L., \& Corry, R. (2016). Body-worn video: A systematic review of literature. Australian \& New Zealand Journal of Criminology, 50(3), 379-396. https://doi.org/10.1177/0004865816638909

Demir, M. (2019). Citizens' perceptions of body-worn cameras (BWCs): Findings from a quasirandomized controlled trial. Journal of Criminal Justice, 60, 130-139. https://doi.org/10.1016/j.jcrimjus.2018.09.009

Drover, P., \& Ariel, B. (2015). Leading an experiment in police body-worn video cameras. International Criminal Justice Review, 25(1), 80-97. https://doi.org/10.1177/1057567715574374

Gau, J. (2014). Procedural justice and police legitimacy: A test of measurement and structure. American Journal of Criminal Justice, 39(2), 187-205. https://doi.org/10.1007/s12103-013-9220-8

Gelo, O., \& Gallucci, M. (2016). Quantitative research. In H. Miller (Ed.), The SAGE encyclopedia of theory in psychology (pp. 781-784). SAGE Publications, Inc. https://www.doi.org/10.4135/9781483346274.n269

Graham, A., McManus, H. D., Cullen, F. T., Burton, V. S., \& Jonson, C. L. (2019). Videos don't lie: African-Americans' support for body-worn cameras. Criminal Justice Review, 44(3), 284-303. https://doi.org/10.1177/0734016819846229

Ingham-Broomfield, R. (2014). A nurses' guide to qualitative research. The Australian Journal of Advanced Nursing: A Quarterly Publication of the Royal Australian Nursing Federation, 32(3), 34. https://search.informit.com.au/documentSummary; $\mathrm{dn}=1$ 16609264549547;res=IELAPA

Jennings, W. G., Fridell, L. A., \& Lynch, M. D. (2014). Cops and cameras: Officer perceptions of the use of body-worn cameras in law enforcement. Journal of Criminal Justice, 42(6), 549-556. https://doi.org/10.1016/j.jcrimjus.2014.09.008

Kahn, K. B., \& Martin, K. D. (2016). Policing and race: Disparate treatment, perceptions, and policy responses. Social Issues \& Policy Review, 10(1), 82-121.

https://doi.org/10.1111/sipr.12019

Krieger, N., Kiang, M., Chen, J., \& Waterman, P. (2015). Trends in US deaths due to legal intervention among Black and White men, age 15-34 years, by county income level: 1960-2010. Harvard Public Health Review, 3, 1-5.

Lum, C., Stoltz, M., Koper, C. S., \& Scherer, J. A. (2019). Research on body-worn cameras. Criminology \& Public Policy, 18(1), 93-118. https://doi.org/10.1111/1745-9133.12412

McCluskey, J. D., Uchida, C. D., Solomon, S. E., Wooditch, A., Connor, C., \& Revier, L. (2019). Assessing the effects of body-worn cameras on procedural justice in the Los Angeles police department. Criminology, 57(2), 208-236. https://doi.org/10.1111/1745-9125.12201 
Meares, T. L., Tyler, T. R., \& Gardener, J. (2015). Lawful or fair? How cops and laypeople perceive good policing. The Journal of Criminal Law and Criminology (1973-), 105(2), 297-343. https://www.jstor.org/stable/26402450

Passavant, P. A. (2015). I can't breathe: Heeding the call of justice. Law, Culture and the Humanities, 11(3), 330-339. https://doi.org/10.1177/1743872115581759

Peck, J. H. (2015). Minority perceptions of the police: A state-of-the-art review. Policing: An International Journal of Police Strategies \& Management, 38(1), 173-203. https://doi.org/10.1108/pijpsm-01-2015-0001

Pollock, W., \& Menard, S. (2015). Perceptions of unfairness in police questioning and arrest incidents: Race, gender, age, and actual guilt. Journal of Ethnicity in Criminal Justice, 13(3), 237-253. https://doi.org/10.1080/15377938.2015.1015197

Ray, R., Marsh, K., \& Powelson, C. (2017). Can cameras stop the killings? Racial differences in perceptions of the effectiveness of body-worn cameras in police encounters. Sociological Forum, 32, 1032-1050. https://doi.org/10.1111/socf.12359

Smith, Y. (2020). The African-American perception of body-worn cameras on police performance and fairness (Publication No. 28151961) [Doctoral Dissertation, Capella University]. ProQuest Dissertations and Theses Global.

Smykla, J. O., Crow, M. S., Crichlow, V. J., \& Snyder, J. A. (2016). Police body-worn cameras: Perceptions of law enforcement leadership. American Journal of Criminal Justice, 41(3), 424-443. https://doi.org/10.1007/s12103-015-9316-4

Taylor, E. (2016). Lights, camera, redaction... police body-worn cameras: Autonomy, discretion, and accountability. Surveillance \& Society, 14(1), 128-132. https://doi.org/10.24908/ss.v14i1.6285

Thompson, C. B., \& Panacek, E. A. (2007). Research study designs: Non-experimental. Air Medical Journal, 26(1), 18-22. https://doi.org/10.1016/j.amj.2006.10.003

Tyler, T. R. (1988). What is procedural justice?: Criteria used by citizens to assess the fairness of legal procedures. Law \& Society Review, 22(1), 103-135. https://doi.org/10.2307/3053632

Van Craen, M. (2016). Fair policing from the inside out. The Politics of Policing: Between Force and Legitimacy-Sociology of Crime, Law, and Deviance, 21(1) 3-19. https://doi.org/10.1108/s1521-613620160000021001

Van Craen, M., \& Skogan, W. G. (2017). Achieving fairness in policing. Police Quarterly, 20(1), 3-23. https://doi.org/10.1177/1098611116657818

White, M. D., Todak, N., \& Gaub, J. E. (2017). Assessing citizen perceptions of body-worn cameras after encounters with police. Policing: An International Journal of Police Strategies \& Management, 40(4), 689-703. https://doi.org/10.1093/police/paw057 